\title{
Retardation of pubertal development by prenatal long days in goat kids born in autumn
}

\author{
S. Deveson ${ }^{1}$, I. A. Forsyth ${ }^{2}$ and J. Arendt ${ }^{1}$ \\ ${ }^{1}$ School of Biological Sciences, University of Surrey, Guildford, Surrey GU2 5XH, UK; and \\ ${ }^{2}$ AFRC Institute of Animal Physiology and Genetics Research, Cambridge Research Station, \\ Babraham, Cambridge CB2 4AT, UK
}

\begin{abstract}
Summary. Goat kids born in spring attain sexual maturity during the first autumn after birth in temperate regions, at about 30 weeks of age. This study observed sexual development in autumn-born kids and the influence of late-summer, prenatal light treatment on onset of puberty. The breeding season of 14 female British Saanen dairy goats was artificially advanced by 4 months, using a treatment of long days during the winter followed by melatonin treatment in spring. Five goats were treated with a photoperiod of $20 \mathrm{~h}$ light: $4 \mathrm{~h}$ dark (lights on $04.00 \mathrm{~h}$ ) for $62 \cdot 1 \pm 1.4$ days (mean \pm SEM, $n=5$ ) prepartum (14 August to 15 October). The remaining nine goats were kept under a natural photoperiod: 20 kids from these mothers were followed, five males and five females from each group. Testicular development was assessed by means of weekly measurement of scrotal circumference. Blood samples were taken once a week from all kids from 4 weeks of age for 5 months. Plasma was assayed for progesterone in females and testosterone in males. Autumn-born female kids initiated oestrous cyclicity in January, at a mean age of $12.8 \pm 0.8$ weeks. Puberty onset was significantly delayed $(P<0.03$, unpaired Student's $t$ test) in females exposed to $20 \mathrm{~h}$ light: $4 \mathrm{~h}$ dark in utero and occurred at a mean age of $16.5 \pm 1.4$ weeks. Testicular development was significantly delayed and plasma testosterone concentrations were lower in autumn-born male kids that experienced $20 \mathrm{~h}$ light: $4 \mathrm{~h}$ dark in utero than in kids from mothers in a natural photoperiod. Late-summer, long-day treatment in utero seasonally phasedelayed onset of puberty in female goat kids and sexual development in male goat kids. The goat fetus appears to detect photoperiod before birth, possibly via the maternal melatonin signal.
\end{abstract}

Keywords: puberty; photoperiod; birth date; testes; goat

\section{Introduction}

In nonequatorial climates, goats are seasonal, short-day breeders, initiating reproductive activity in response to decreasing daylength during the autumn (Shelton, 1978; Lincoln \& Short, 1980; Karsch et al., 1984). This adaptive feature of their reproductive strategy enables them to give birth in the spring, when climatic conditions and food availability are optimum for the growth and survival of the offspring. Goats born at the natural time of year (spring) reach puberty during the autumn after birth, at about 30 weeks old (Ricordeau et al., 1984). Puberty onset in sheep (also short-day breeders) may occur by an interaction between physical maturity and photoperiod (Foster \& Ryan, 1981); photoperiod can induce puberty onset only if the reproductive axis is sufficiently developed (Foster, 1981; Foster, 1983; Nowak \& Rodway, 1985; Foster et al., 1986, 1989; Ebling \& Foster, 1989). However, the regulation of sexual development, so that onset of puberty occurs at the appropriate time of year in short-day breeding mammals, 
is complex, involving numerous environmental and developmental factors (Foster et al., 1989).

During their first season, male goats can be used successfully to mate females but over use is not advised. Female goats, however, are recommended to be at least $60-70 \%$ of adult weight before being mated. This ensures the physical maturity to carry a successful pregnancy (Shelton, 1978). Females, therefore, are not usually allowed to mate until their second autumn, when 18 months old. Autumn-born goats could be mated the summer after birth, when barely a year old, if they are sexually mature. This would increase herd production by reducing the time-lag between birth and first breeding season.

In the present study pubertal development was monitored in autumn-born female and male goat kids and the effect of exposure to long days in utero on puberty was observed.

\section{Materials and Methods}

\section{Animals and treatment}

Fourteen pregnant goats, of the British Saanen dairy breed, were induced to breed out of season using a treatment combining exposure to a photoperiod of $20 \mathrm{~h}$ light: $4 \mathrm{~h}$ dark (lights on at $04.00 \mathrm{~h}$ ) for 2 months during the winter, followed by 3 months of oral melatonin treatment $(3 \mathrm{mg}$ daily at $16.00 \mathrm{~h}$, Deveson et al., in press). During light treatment, they were housed at ambient temperature in light-controlled loose boxes equipped with programmable light-timers (MK Electric Ltd, Shrubbery Road, Edmonton, London N9 OPB, UK) controlling tungsten-halogen lamps ( $300 \mathrm{~W}$, Power Lite Okay 300, British Lighting Institute, Reading, Berks, UK). They were fed a daily diet of $1 \mathrm{~kg}$ concentrates as pellets containing $18 \%$ protein (prepared on the farm; AFRC Institute of Grassland and Environmental Research, Shinfield, Reading, UK), with water and silage ad libitum. These animals produced kids on 15 October $1989 \pm 1 \cdot 4$ days, mean \pm SEM, $n=14), 4$ months earlier than the rest of the herd.

\section{Experimental protocol}

The pregnant goats were assigned to two groups: group 1 consisted of five goats which were exposed to $20.00 \mathrm{~h}$ light:4.00 h dark (lights on at 04:00 BST; light intensity at level of goat's eye at 11:00 h BST, natural light: $2510 \pm$ $697 \mathrm{~lx}$, artificial light at night: $379 \pm 71 \mathrm{~lx}$; mean \pm SEM, $n=16$ ) for $62 \pm 1.4$ days (mean \pm SEM, $n=5$ ) before their predicted date of producing kids (light treated 14 August-15 October \pm 1.4 days). On the day kids were produced, the goats were returned to a natural photoperiod without further treatment. Group 2 consisted of nine goats that were housed under a natural photoperiod at $52^{\circ} 14^{\prime} \mathrm{N}$ throughout. Goats produced kids in separate pens in the main goat house.

The kids were removed from their mothers when 2 days old and housed in a natural photoperiod. Calf milk replacer was supplied ad libitum from an artificial udder. At 4 weeks of age the kids were weaned and fed daily with $0.3 \mathrm{~kg}$ concentrates. After weaning, they were removed to another pen and housed under a natural photoperiod and at ambient temperature at $52^{\circ} 15^{\prime} \mathrm{N}$ (Reading) throughout the experiment. At the end of the 6 month observation period all the kids were weighed.

Pubertal development of 20 kids was followed (five male and five female goats from each group of mothers): group 1: two sets of male twins and one male from a twin birth, one set of female triplets and two females from twin births; group 2: four males from twin births and one from triplets, two females from twin births, two singletons and one from a triplet birth. Thus all but two kids were derived from multiple births. Testicular development was assessed in male kids by taking measurements of scrotal circumference at the widest point, using a calibrated flexible measuring device. Testicular development was followed from birth for 6 months. From 4 weeks of age, blood samples were collected once a week by venepuncture in the left external jugular vein from all kids. Blood was taken between 11.00 and $12,00 \mathrm{~h} \mathrm{GMT}$, weekly for 5 months. Plasma was collected and assayed for progesterone (females) and testosterone (males).

\section{Progesterone assay}

Plasma from female kids was assayed for progesterone using an enzyme-linked immunosorbent assay (ELISA) by the original method of Sauer et al. (1981; modified to use the progesterone-11-glucuronide alkaline phosphatase conjugate by Sauer et al., 1986). The assay was further modified to measure the plasma progesterone concentrations usually observed in goats during oestrus and early pregnancy (range of standard curve; $0-20 \mathrm{ng} \mathrm{ml}^{-1}$ or $63 \cdot 59 \mathrm{nmol}$ $1^{-1}$ ). Goat anti-progesterone 11-hemisuccinate antiserum (batch S1 509/16) was donated by $\mathbf{J}$. Foulkes, Ministry of Agriculture, Food and Fisheries (MAFF) Cattle Breeding Centre, Shinfield, Reading, and used at a final dilution of $1: 4000$ in $0.15 \mathrm{mmol}$ sodium acetate $1^{-1}(\mathrm{pH} 9.0)$, as assessed by antiserum dilution curves. The conjugate 
was donated by M. Sauer (MAFF Cattie Breeding Centre, Shinfield) and used at a final dilution of 1:10 000 in assay buffer (phosphate-buffered saline plus $0 \cdot 1 \%(\mathrm{w} / \mathrm{v})$ azide and $0 \cdot 1 \%(\mathrm{w} / \mathrm{v})$ gelatin, $\mathrm{pH} 7 \cdot 0)$. The assay was set up on hard polyvinylchloride microtitre plates (Nunc or Immulon microelisa plates: Dynatech Laboratories Ltd, Billingshurst, Sussex, UK). The ELISA method (Sauer et al., 1986) was used and the minimum concentration of progesterone that could be detected in plasma of goats was $1.34 \mathrm{nmol}^{-1}$. Recovery of progesterone from plasma pools containing 1.91, 29.89 and $57.24 \mathrm{nmol}$ progesterone $\mathrm{1}^{-1}$ was 108,134 and $89 \%(n=4)$, respectively. Mean intra-assay variability over the range of the standard curve was $3.7 \pm 0.9 \%$ (mean coefficient of variation \pm SEM, $n=8$ ), and interassay coefficients of variation of plasma progesterone pools containing 5.09 and $9.86 \mathrm{nmol}^{-1}$ were 8.1 and $7.8 \%(n=5)$, respectively.

\section{Testosterone assay}

Diethyl ether extracts of plasma from male kids were assayed for testosterone by a modification of the radioimmunoassay of Corker \& Davidson (1978). A bovine anti-testosterone monoclonal antibody, developed and donated by D. Groves (University of Surrey, Guildford) was prepared according to the method of Groves et al. (1987). Crossreactivities for the bovine anti-testosterone monoclonal antibody were as follows; testosterone, $100 \%$; dihydrotestosterone, $87 \%$; androstenedione, $0.02 \%$; oestradiol, $<0.02 \%$; oestrone, $<0.02 \%$ and progesterone, $<0.02 \%$. By means of antiserum dilution curves the final working dilution of this antiserum was found to be $1: 75$ in phosphate-buffered saline containing $0.1 \%(\mathrm{w} / \mathrm{v})$ azide and $0.1 \%(\mathrm{w} / \mathrm{v})$ gelatin, $\mathrm{pH} 7 \cdot 0$. Tritiated testosterone (specific activity; $93 \mathrm{Ci} \mathrm{mmol}^{-1}$ ) was supplied by Amersham International plc (Amersham, Bucks, UK). The minimum amount of testosterone that could be detected in plasma of goats was $0.53 \mathrm{nmol}^{-1}$. Recovery of testosterone from plasma pools containing $2.93,3.28$ and $5.99 \mathrm{nmol}$ testosterone $1^{-1}$ was 116,114 and $96 \%$, respectively. Mean intraassay variability across the range of the standard curve was $3.4 \pm 1.2 \%$ (mean coefficient of variation $\pm \operatorname{SEM}, n=8$ ), and interassay coefficients of variation of plasma testosterone pools containing $2.49,4.43$ and $8.75 \mathrm{nmol}^{-1}$ were 13.2 , $15 \cdot \mathrm{I}$ and $11 \cdot 6 \%(n=4)$, respectively.

\section{Statistical analysis}

The statistical significance of differences in the age of puberty onset (defined as progesterone levels greater than I ng ml $\mathrm{I}^{-1}$ in two consecutive samples) in females, and live body weight, between groups of kids, were calculated using a one-way analysis of variance and an unpaired Student's $t$ test as appropriate. For the measurements of testes circumference a Kolmogorov-Smirnoff goodness-of-fit test was used to assess whether the data were normally distributed. A repeated measures analysis of variance was used to test for an overall treatment effect and a time by treatment interaction to assess whether there were significant differences between treatment groups 1 and 2 with respect to testes circumference. A one-way analysis of variance on square-root-transformed data, followed by Duncan's multiple range test, was then used to determine where the significant differences lay. Plasma testosterone concentrations in each group of male kids were compared using a two-way analysis of variance with replication to test for an overall treatment effect.

\section{Results}

The duration of pregnancy was not affected by exposure of dams to long days (group 1: $20.00 \mathrm{~h}$ light:4.00 h dark: $144.2 \pm 0.5$ days; group 2: natural photoperiod: $147.8 \pm 1.9$ days, mean \pm SEM, $n=5$ in group 1 and $n=9$ in group 2). Figure 1 is a schematic diagram indicating the onset of puberty in the autumn-born female goats, and the effect of in utero $20.00 \mathrm{~h}$ light: $4.00 \mathrm{~h}$ dark photoperiod treatment on the timing of puberty. Progesterone concentrations greater than $1 \mathrm{ng} \mathrm{ml}^{-1} \mathrm{on}^{-}$ two consecutive sampling occasions was taken to indicate an oestrous cycle. Onset of puberty was taken to be the presence of at least two ovarian cycles, shown by cyclical increases in plasma progesterone. Autumn-born female kids from mothers in group 1, exposed to $20.00 \mathrm{~h} \mathrm{light:04.00 \textrm {h }}$ dark prepartum, reached puberty at a mean age of $16.5 \pm 1.4$ weeks (mean \pm SEM, $n=5$ ), significantly later $(3.7$ weeks, $P<0.03)$ than autumn-born kids from mothers in group 2 , exposed to natural photoperiod prepartum. The latter attained puberty at a mean age of $12 \cdot 8 \pm 0 \cdot 2$ weeks (mean $\pm \mathrm{SEM}, n=5$ ). There were no significant differences between the mean live body weight of females from mothers in both groups at the end of the experiment (group $1 \mathrm{kids}: 22.4 \pm 0.6 \mathrm{~kg}$; group 2 kids: $23.5 \pm 0.9 \mathrm{~kg}$, mean $\pm \mathrm{SEM}, n=5$ per group).

In autumn-born male kids from mothers in group 2 (natural light), testosterone remained low $\left(<10 \mathrm{nmol} \mathrm{l}^{-1}\right)$ until 14 weeks of age and rose over the next 4 weeks, declining again after 
(a)

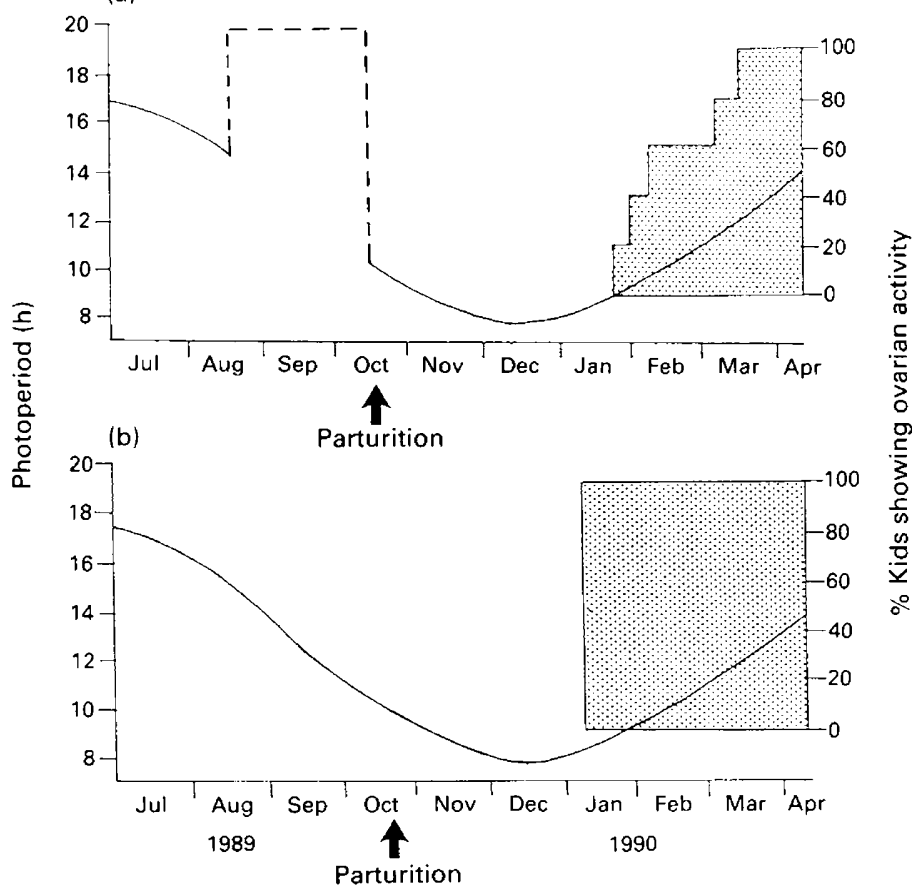

Fig. 1. Diagram showing the onset of puberty in autumn-born female goat kids and (a) the effect of in utero treatment for 2 months before birth with $20 \mathrm{~h}$ light: $4 \mathrm{~h}$ dark on the timing of puberty; (b) natural light. Progesterone $>1 \mathrm{ng} \mathrm{ml}^{-1}$ on two consecutive sampling occasions

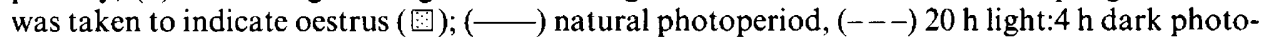
period; arrows: mean birth date for each group. Unpaired Student's $t$ test indicated that group 1 female kids reached puberty significantly later $(P<0.03)$ than group 2 female kids $(16.5 \pm 1.4$ weeks of age versus $12 \cdot 8 \pm 0 \cdot 2$ weeks of age, means \pm SEM, $n=5$ ).

mid-February to $<4 \mathrm{nmol}^{-1}$ by the second week in April (Fig. 2). Mean plasma testosterone concentrations during the 5 month assessment period were consistently greater than in kids from mothers kept in $20.00 \mathrm{~h}$ light:04.00 h dark (group 1). However, there was not an overall significant difference between treatment groups with respect to plasma testosterone ( $\mathrm{F}$ ratio [degrees of freedom]: $F s[37,1]=1 \cdot 447 ; P=0 \cdot 117)$, but variation of testosterone with time $(\mathrm{Fs}[18,1]=5 \cdot 131$; $P<0.0001)$ and differences between animals in each group (Fs $[189,18]=7 \cdot 373 ; P=0 \cdot 007)$ were highly significant. A Kolmogorov-Smirnoff goodness-of-fit test indicated that the testes circumference data followed a normal distribution. A repeated measures analysis of variance was used and with treatment and time as main factors, scrotal circumference in kids from mothers in group 2 was significantly greater than scrotal circumference in kids from mothers in group 1 overall $(\mathrm{Fs}[1,8]=$ $7.89 ; P=0.023$ ), and with a treatment by time interaction (Fs $[20,160]=1 \cdot 71 ; P=0.037)$ (Fig. 3). A one-way analysis of variance on square-root transformed data indicated a highly significant difference between groups $(P<0.0001)$. There were no significant differences between groups in the mean live body weight of the male kids at the end of the experiment (group 1 kids; $28.1 \pm 1.6 \mathrm{~kg}$; group $2 \mathrm{kids} ; 30.5 \pm 0.9 \mathrm{~kg}$, mean $\pm \mathrm{SEM}, n=5$ per group).

\section{Discussion}

The two groups of female kids used in this study were not stictly comparable in that two singleton births were included in the natural light group and a set of triplets in the prenatal light treatment 
(a)

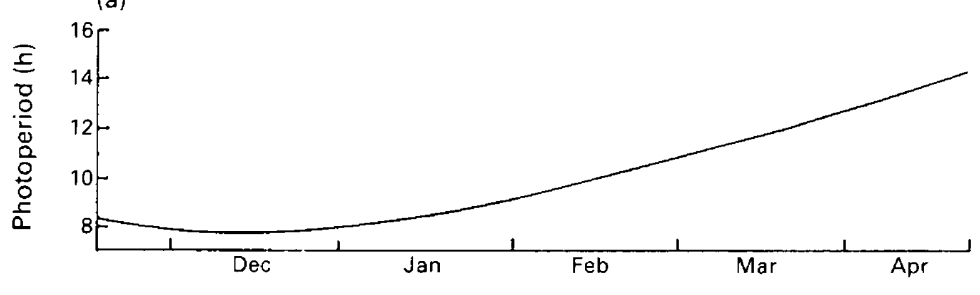

(b)

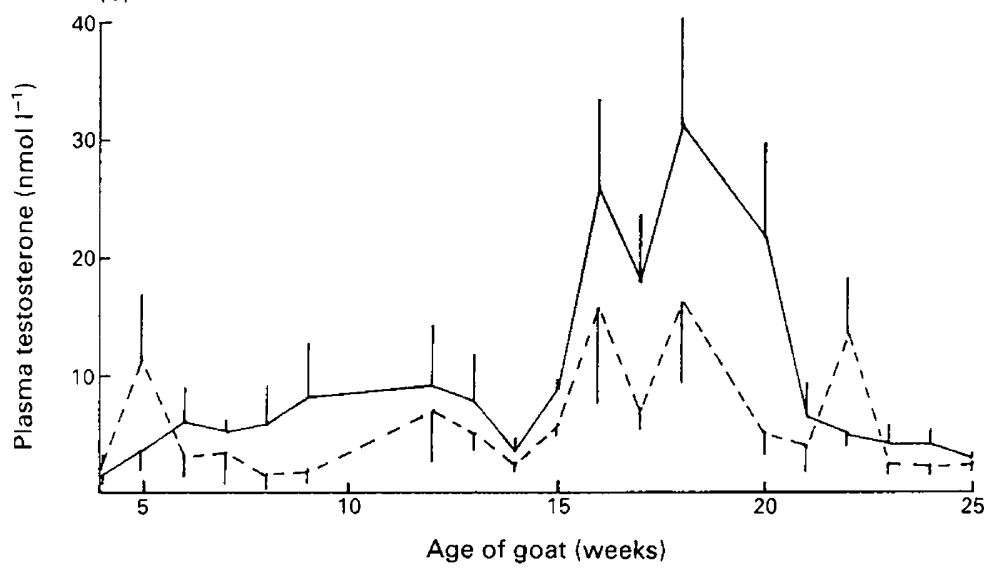

Fig. 2. (a) Photoperiod for period under study. (b) Plasma testosterone concentrations in autumn-born male goat kids, taken for 5 months from 4 weeks of age and the effect of in utero treatment with $20 \mathrm{~h}$ light: $4 \mathrm{~h}$ dark for 2 months before birth (-- ) or natural light (-). There were no significant differences between groups (two-way analysis of variance with replication).

group. Birthweights of this group were not recorded, but in the Shinfield herd significant differences exist between types of birth (e.g. in 1989 , singletons, $4.28 \pm 0.75 \mathrm{~kg}, n=6$; twins, $4.0 \pm 0.56 \mathrm{~kg}$, $n=80$; triplets, $3.65 \pm 0.92 \mathrm{~kg}, n=45, x \pm \mathrm{SD}$ ). The question thus arises as to whether the presumed differences in birthweight influenced pubertal development. Evidence from the literature indicates that this is not the case for kids born in the natural season: Ricordeau et al. (1984) in an extensive review reported that type of birth (singleton, twin or triplet) does not influence the date of first oestrus. Live body weight did however correlate significantly with date of first oestrus (Ricordeau et al., 1984). Live weight at puberty is very variable, ranging from 21.5 to $38.5 \mathrm{~kg}$ in the Shinfield herd (Amoah \& Bryant, 1984a, b) and thus, in the natural season, may not play a critical role in determining the date of first oestrus. Moreover, live weight at 4 months of age does not correlate with birthweight in Shinfield Saanens reared on milk replacers (J. Cook, pers. commun.). For kids born in the natural season (as for lambs, Hafez, 1952), birthweight and type of birth do not therefore appear to influence the timing of puberty. We consider it unlikely that our observations are compromised by the composition of the female groups, but as there is no available information on these factors in kids born out of season this possibility cannot be ruled out.

Ricordeau et al. (1984) reported a mean age at puberty of 32.8 weeks for 1300 goats born from January through to March at $44^{\circ} \mathrm{N}$. In this respect, goats closely resemble sheep (puberty occurs at 30-35 weeks in female lambs; see Foster, 1988). However, goats are reputed to be precocious in their reproductive development and individual instances of puberty in female goats from about 12 weeks of age have been reported (see Amoah \& Bryant, 1984a, b). In keeping with this, puberty occurred at $12 \cdot 8 \pm 0.2$ weeks of age in autumn (October)-born female goat kids. This is in marked contrast to observations in sheep. Autumn-born female lambs raised in natural photoperiods delay 


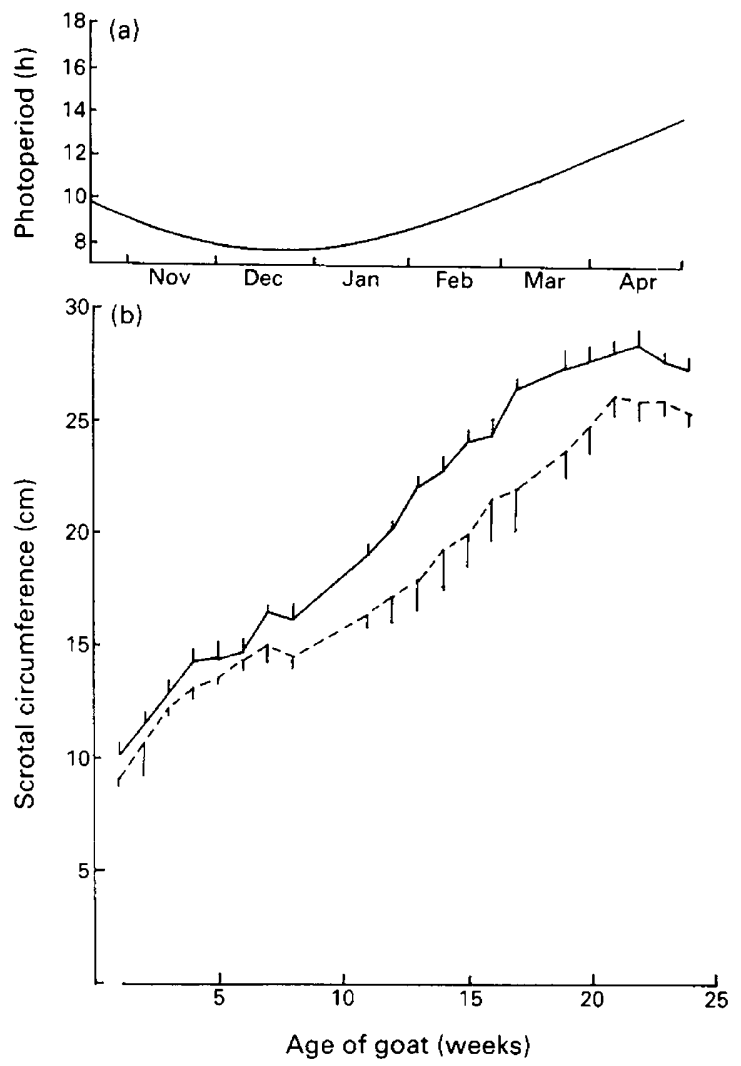

Fig. 3. (a) Photoperiod for period under study. (b) Scrotal circumference in autumn-born goat kids during the first 6 months of life and the effect of in utero treatment with $20 \mathrm{~h}$ light: $4 \mathrm{~h}$ dark $(--)$ or natural light $(-)$. All points are means \pm SEM, $n=5$. Repeated measures ANOVA indicated significantly greater scrotal circumference in the natural light kids $(P=0.023)$ with a treatment by time interaction $(P=0.037)$.

onset of puberty to the breeding season almost a year after birth (Hammond, 1944), but respond to an annually-reversed photoperiod with puberty at the usual age of $35 \pm 0.5$ weeks (Foster, 1981; Foster \& Ryan, 1981). Experiments by Foster and co-workers have examined the photoperiodic sequence necessary for the occurrence of puberty in female sheep (Yellon \& Foster, 1986; Foster et al., 1988a, b, c, 1989; Ebling et al. 1988; Ebling \& Foster, 1989) and have demonstrated that exposure to long days determines the timing of onset of puberty. A period of long-day light exposure at about 18-23 weeks of age was essential for puberty to occur at the natural age of 30 weeks. Neonatal exposure to short days was not necessary for subsequent recognition of long-day photoperiods. Long daylengths timed puberty, which occurred in the absence of any additional photoperiodic information, for example in superior cervical ganglionectomized lambs receiving only a long-day melatonin infusion for 5 weeks from 18 weeks of age (Foster et al., 1988c). However, continued long artificial photoperiods disrupt puberty onset in female sheep isolated from mature males (Yellon \& Foster, 1985).

The growth requirement for puberty appears to be less in goats than in sheep. Amoah \& Bryant (1984a) report the ratio of live weight at puberty in proportion to the average adult live weight for British Saanen goats as 0.36 . This value is similar to the ratio observed for the goats in the present study at 6 months of age and is low by comparison with values of $0.51-0.69$ reported for most sheep breeds (Dyrmundsson, 1973a). 
By comparison with sheep (Dyrmundsson, 1973b) there have been rather few studies of puberty in male goats. Yao \& Eaton (1954) reported that in Toggenburg and mixed breeds the growth of the testes was independent of birthweight. They found spermatozoa in the testes from the early age of 13 weeks and recommended separation of bucks from does at about 11 weeks. In spring-born male Nubian goats, rises in serum testosterone concentration first occurred between 17 and 20 weeks of age, and some goats showed mounting behaviour from 16 weeks. However, puberty, as defined by collection of an electro-ejaculate containing motile spermatozoa, did not occur until $32.4 \pm 0.9$ weeks at a mean body weight of $37.7 \mathrm{~kg}$ (Chakraborty et al., 1989). By the same criterion, Libyan male goats born at $32^{\circ} 56^{\prime} \mathrm{N}$ in late January were sexually mature at $27 \cdot 4 \pm 1.0$ weeks and $22 \mathrm{~kg}$ (Madani \& Kahal, 1988). In the present experiments an increase in plasma testosterone concentration began at 14 weeks of age, in autumn-born male goats.

One of the main aims of the present experiment was to determine whether exposure of late pregnant goats to long daylengths, as a procedure to manipulate breeding seasons, has any effect on puberty in their offspring. Amoah \& Bryant (1984a) studied early (March-April)- and late (AprilMay)-born female goat kids run with vasectomized males. They found that step-wise reduction of daylength from $18.00 \mathrm{~h}$ light:6.00 h dark to $10.00 \mathrm{~h}$ light: $14.00 \mathrm{~h}$ dark over 10 weeks, starting at 6 or 10 weeks of age, advanced puberty compared with constant long days ( $18.00 \mathrm{~h}$ light:6.00 h dark), especially in early born kids. Similarly in male Libyan goats, birth into a decreasing photoperiod was associated with earlier development of puberty (Madani \& Kahal, 1988). However, exposure of spring-born male goat kids in utero to long or short days during the last third of pregnancy had no effect on subsequent testis development (Hochereau de Reviers et al., 1986).

In sheep (Yellon \& Longo, 1987, 1988; Zemdegs et al., 1988; McMillan \& Nowak, 1989) circadian rhythms of fetal melatonin have been demonstrated, derived from the maternal circulation via transplacental transfer. Moreover manipulation of photoperiod and melatonin administration can influence prolactin secretion in the fetus (Bassett et al., 1989). Thus, it appears that sheep fetuses detect photoperiod-dependent changes in melatonin in utero and the lamb acquires a photoperiodic history before it is born (Ebling \& Foster, 1989). In the present study light exposure in utero delayed sexual development in both female and male autumn-born goats (Figs 1 and 2). The following theory is advanced to explain these results, based on observations in lambs. When in utero, the goat fetus detected photoperiod via transplacental passage of the melatonin signal of the mother. Having mated in May, the mothers in natural photoperiods were exposed to long days through to August and a long-day pattern of melatonin secretion was transferred from mother to fetus. This signal prepared the fetus for detection of photoperiod after birth. The female kids were born into and could respond to a shortening photoperiod in the autumn, timing the onset of puberty to 13 weeks after birth, and indicating less dependence on body size and much earlier maturation of the hypothalamic GnRH pulse generator compared with sheep (see Foster et al., 1986). Exposure of mothers to $20.00 \mathrm{~h}$ light: $04.00 \mathrm{~h}$ dark for the last 2 months of pregnancy extended the fetal exposure to a long-day signal and phase-delayed sexual maturation, which occurred 16.5 weeks after birth in females. Sexual development was similarly delayed in males.

The raising together of male and female kids could have influenced the results obtained. However, it is probable that any effect of males was minimized by the continuous nature of interactions, by contrast with signals provided by introducing mature males to pre-pubertal females (Amoah \& Bryant, 1984b), although this requires further investigation.

These experiments were conducted while I. A. Forsyth was a member of the staff of the AFRC Institute of Grassland and Environmental Research, Hurley Research Station, Hurley, Maidenhead, Berks. We would like to thank J. Adlam, D. Webster, S. Gardiner and S. Lane for daily care of the animals. We are indebted to M. Sauer, J. Foulkes (both at MAFF Cattle Breeding Centre, Shinfield, Reading, Berks, UK) and D. Groves (presently at Cybus Bioscience Ltd, Epsilon House, Chilworth Research Centre, Southampton, UK) for the donations of the progesterone conjugate, progesterone antiserum and testosterone antiserum, respectively. 


\section{References}

Amoah, E.A. \& Bryant, M.J. (1984a) Effect of pattern of lighting and time of birth on occurrence of puberty in female goat kids. Animal Production 38, 83-89.

Amoah, E.A. \& Bryant, M.J. (1984b) A note on the effect of contact with male goats on occurrence of puberty in female goat kids. Animal Production 38, 14 I-144.

Bassett, J.M., Curtis, N., Hanson, C. \& Weeding, C.M. (1989) Effects of altered photoperiod or maternal melatonin administration on plasma prolactin in fetal lambs. Journal of Endocrinology 122, 633-643.

Corker, C.S. \& Davidson, D.W. (1978) The radioimmunoassay of testosterone in various biological fluids without chromatography. Steroid Biochemistry 9, 373-374.

Chakraborty, P.K., Stuart, L.D. \& Brown, J.L. (1989) Puberty in the male Nubian goat: serum concentrations of LH, FSH and testosterone from birth through puberty and semen characteristics at sexual maturity. Animal Reproduction Science 20, 91-101.

Deveson, S.L., Arendt, J. \& Forsyth, I.A. Induced out-ofseason breeding in maiden and dry pregnant dairy goats: use of artificial photoperiod and/or melatonin administration. Animal Reproduction Science (in press).

Dyrmundsson, O.R. (1973a) Puberty and early reproductive performance in sheep: I ewe lambs. Animal Breeding Abstracts 41, 273.

Dyrmundsson, O.R. (1973b) Puberty and early breeding performance in sheep: II ram lambs. Animal Breeding Abstracts 41, 419-429.

Ebling, F.J.P. \& Foster, D.L. (1989) Pineal melatonin rhythms and the timing of puberty in mammals. Experientia 45, 946-955.

Ebling, F.J.P., Claypool, L.E. \& Foster, D.L. (1988) Neuroendocrine responsiveness to light during the neonatal period in the sheep. Journal of Endocrinology $199,211-218$.

Foster, D.L. (1981) Mechanism for delay of first ovulation in lambs born in the wrong season (Fall). Biology of Reproduction 25, 85-92.

Foster, D.L. (1983) Photoperiod and sexual maturation of the female lamb: early exposure to short-days perturbs estradiol negative feedback inhibition of $\mathrm{LH}$ secretion and produces abnormal ovarian cycles. Endocrinology 112, $11-17$.

Foster, D.L. (1988) Puberty in the female sheep. In The Physiology of Reproduction, pp. 1739-1762. Eds E. Knobil \& J. Neill. Raven Press, New York.

Foster, D.L. \& Ryan, K.D. (1981) Endocrine mechanisms governing transition into adulthood; a marked decrease in inhibitory action of estradiol on tonic secretion of luteinizing hormone in the lamb during puberty. Endocrinology 105, 896-904.

Foster, D.L., Karsch, F.J., Olster, D.H., Ryan, K.D. \& Yellon, S.M. (1986) Determinants of puberty in a seasonal breeder. Recent Progess in Hormone Research 42, 330-379.

Foster, D.L., Ebling, F.J.P. \& Claypool, L.E. (1988a) Timing of puberty by photoperiod. Reproduction Nutrition Development 28, 349-364.

Foster, D.L., Ebling, F.J.P., Claypool, L.E. \& Woodfill, C.J.(1988b) Cessation of long-day melatonin rhythms times puberty in a short-day breeder. Endocrinology 123, $1636-1641$.

Foster, D.L., Yellon, S.M., Ebling, F.J.P. \& Claypool, L.E. (1988c) Are ambient short-day cues necessary for puberty in a short-day breeder? Biology of Reproduction 38, 821-829.

Foster, D.L., Ebling, F.J.P., Claypool, L.E., Wood, R.I., Adel, T.E. \& Schraman, W. (1989) Amplitude modulation of the nightly melatonin rise in the neonatal lamb and the subsequent timing of puberty. Biology of Reproduction 40, 920-928.

Groves, D.J., Morris, B.A. \& Clayton, J. (1987) Preparation of bovine monoclonal antibody to testosterone by interspecies fusion. Research in Veterinary Science 43, 253-256.

Hafez, E.S.E. (1952) Studies on the breeding season and reproduction of the ewe. Journal of Agricultural Science 42, 189-265.

Hammond, J. (1944) On the breeding season in the sheep. Journal of Agricultural Science 34, 97-105.

Hochereau-de-Reviers, M.T., Perreau, C., Delouis, C., Chemineau, P. \& Courot, M. (1986) Effects of photoperiod during foetal life and of age on total number of Sertoli cells per testis between birth and adulthood in the goat. Biology of Reproduction 34 (Supplement 1); 369 (Abstract).

Karsch, F.J., Bittman, E.L., Foster, D.L., Goodman, R.L., Legan, S.J. \& Robinson, J.E. (1984) Neuroendocrine basis of seasonal reproduction. Recent Progress in Hormone Research 40, 185-232.

Lincoln, G.A. \& Short, R.V. (1980) Seasonal breeding: nature's contraceptive. Recent Progress in Hormone Research 36, 1-52.

Madani, M.O.K. \& Rahal, M.S. (1988) Puberty in Libyan male goats. Animal Reproduction Science 17, $207-216$.

McMillan, I.C. \& Nowak, R. (1989) Maternal pinealectomy abolishes the diurnal rhythm in plasma melatonin concentrations in the foetal sheep and pregnant ewe during late gestation. Journal of Endocrinology 120, 459-464.

Nowak, R. \& Rodway, R.G. (1985) Effect of intravaginal implants of melatonin on the onset of ovarian activity in adult and prepubertal ewes. Journal of Reproduction and Fertility 74, 287-294.

Ricordeau, G., Bouillan, J., Gaillard, A., Lajous, A. \& Lajous, D. (1984) Modalites et characteristiques de reproduction chez les caprines. Aspects genetiques. Bulletin Technique d'Information INRA 391, 367-383.

Sauer, M.J., Foulkes, J.A. \& Cookson, A.D. (1981) Direct EIA of progesterone in bovine milk. Steroids 38, 45-53.

Sauer, M.J., Foulkes, J.A., Worsford, A. \& Morris, B.A. (1986) Use of progesterone 11-glucuronide alkaline phosphatase conjugate in a sensitive microtitre plate EIA of progesterone in milk and its application to pregnancy testing in dairy cattle. Journal of Reproduction and Fertility 76, 375-392.

Shelton, M. (1978) Reproduction and breeding of goats. Journal of Dairy Science 61, 994-1010.

Yao, T.S. \& Eaton, O.N. (1954) Postnatal growth and histological development of reproductive organs in male goats. American Journal of Anatomy 95, 401-431. 
Yellon,S.M. \& Foster, D.L. (1985) Alternate photoperiods time puberty in the female lamb. Endocrinology 116, 2090-2097.

Yellon, S.M. \& Foster, D.L. (1986) Melatonin rhythms time photoperiod-induced puberty in the female lamb. Endocrinology 119, 44-49.

Yellon, S.M. \& Longo, L.D. (1987) Melatonin thythms in fetal and maternal circulation during pregnancy in sheep. American Journal of Physiology 252, E799-E802.
Yellon, S.M. \& Longo, L.D. (1988) Effects of maternal pinealectomy and reverse photoperiod on the circadian melatonin rhythm in the sheep and fetus during the last trimester of pregnancy. Biology of Reproduction 39, 1093-1100.

Zemdegs, I.Z., McMillan, I.C., Walker, D.W., Thornburn, G.D. \& Nowak, R. (1988) Diurnal rhythms in plasma melatonin concentrations in fetal sheep and pregnant ewe during late gestation. Endocrinology 123, 284-289.

Received 23 May 1991 